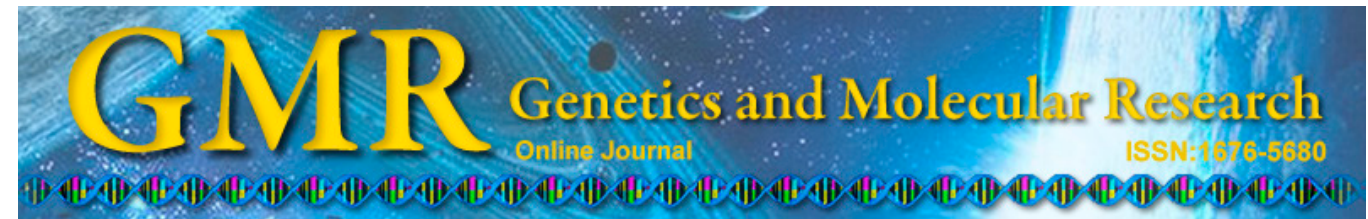

\title{
Molecular detection of human papillomavirus in Brazilian women with cervical intraepithelial neoplasia in a northeast Brazilian city
}

\author{
J.D.C. Nunes ${ }^{1}$, F.C.B. Vidal', C.T.L. Ferraro ${ }^{2}$, M.B.C. Chein ${ }^{1}$, \\ L.M.O. Brito ${ }^{1}$ and S.C.M. Monteiro ${ }^{1}$ \\ ${ }^{1}$ Programa de Pós-Graduação em Saúde Materno-Infantil, \\ Universidade Federal do Maranhão, São Luís, MA, Brasil \\ ${ }^{2}$ Programa de Pós-Graduação em Oncologia, Instituto Nacional de Câncer, \\ Rio de Janeiro, RJ, Brasil \\ Corresponding author: J.D.C. Nunes \\ E-mail: jomdiogo@yahoo.com.br
}

Genet. Mol. Res. 13 (4): 9077-9085 (2014)

Received January 7, 2014

Accepted July 28, 2014

Published October 31, 2014

DOI http://dx.doi.org/10.4238/2014.October.31.23

ABSTRACT. We examined the prevalence of human papillomavirus
(HPV) infection in Brazilian women with cervical intraepithelial
neoplasia. Our goal was to identify the types of HPV and their association
with risk factors. This prospective cross-sectional study included 97
samples collected from women aged $14-79$ years at the public health
units of gynecological care in São Luís, MA, Brazil. HPV detection was
performed by nested polymerase chain reaction and sequence analysis.
The study patients completed a structured questionnaire to provide
information regarding their socio-demographic, clinical, and behavioral
status. HPV prevalence was found to be $80.4 \%$, with 17 virus types
detected, including HPV $16,18,58,6$, and 11 . Significant associations
between HPV infection and age and frequency of doctor visits were
identified. The study findings indicate the significance of age and low
frequency of visits to the gynecologist as risk factors for genital HPV
infection, suggesting that HPV infection-derived cervical cancer could 
be prevented through orientation programs for women, which include sex education and information regarding screening tests. We also found an increased prevalence of high-risk HPV serotypes in cervical lesions, which reveals an association between cervical lesions and high-risk HPV.

Key words: Human papillomavirus; Polymerase chain reaction; Risk factors; Uterine cervical neoplasms

\section{INTRODUCTION}

Cervical cancer is the 3rd most commonly diagnosed cancer in women, 2nd only to breast and colorectal cancer, and the 4th leading cause of cancer-related deaths in women worldwide (Jemal et al., 2011). Cervical cancer accounts for $9 \%$ of new cancer cases among women, accounting for approximately half a million new cases and 200,000 deaths annually, with $85 \%$ of occurring in developing countries.

Epidemiological evidence suggests that human papillomavirus (HPV) is necessary for the development of cervical cancer (Andall-Brereton et al., 2011; Katki et al., 2013). Studies conducted over the past decade have clearly shown that HPV infection precedes the development of cervical cancer and have confirmed that sexual transmission is the predominant mode of HPV acquisition. The estimated global HPV prevalence among women is $11.7 \%$, which shows some variation worldwide between 10 and $25 \%$; the rates are higher for women in Africa, Eastern Europe, and Latin America (Ayres and Silva, 2010; Bruni et al., 2010). Overall, approximately $70 \%$ of cervical cancers are associated with either HPV type 16 or 18 . Other tumorigenic serotypes include HPV 52, 31, and 58 (Bruni et al., 2010; Li et al., 2011).

HPV infection is a necessary condition for the development of cervical cancer, but the presence of HPV infection alone is not sufficient for malignant progression of cervical lesions. In addition to the HPV type, the evolution to malignancy is related to other risk factors (Fernandes et al., 2009).

A large number of women infected with oncogenic HPV types do not develop cervical cancer, indicating that other risk factors are associated with the progression of cervical lesions to malignancy (Fernandes et al., 2009). The development of precancerous lesions to invasive cancers also depends on susceptible host phenotypes, HPV genomic variability, multiplicity of HPV infections, co-infection with other agents (including Chlamydia trachomatis and HIV), and lifestyle (de Freitas et al., 2012).

Understanding the distribution of HPV tumorigenic serotypes may help to prevent cancer in other organs such as the anus, oropharynx, and esophagus. HPV infection in these organs may be related to sexual practices, allowing HPV to penetrate into organs other than the reproductive organs (Zandberg et al., 2013).

The diagnosis of cervical intraepithelial lesions and cancer is primarily based on cytological, histopathological, and clinical examinations.

\section{MATERIAL AND METHODS}

\section{Study population}

This prospective cross-sectional study included 97 women aged 14-79 years who were 
patients at the public health units of gynecological care in São Luís, MA, Brazil, from February 2010 to January 2013. The women showed cytological evidence of atypical squamous cells or history of cervical cancer. Those who were pregnant or at less than 45 days postpartum were excluded from this study.

A standardized questionnaire was used to collect information on the demographic, social, family, and behavioral characteristics of the patients. These data included age, literacy, marital status, ethnicity, age of menarche, age at first intercourse, parity, lifetime number of sexual partners, methods of contraception, frequency of visits to the gynecologist before the diagnosis of intraepithelial lesions, and methods used to diagnose neoplasia.

The project was approved by the Research Ethics Committee, and informed consent was obtained from all subjects.

\section{Specimen collection}

For HPV DNA isolation, samples cervix were collected, placed in the $\mathrm{hc}_{2}$ DNA Collection buffer (Qiagen, Hilden, Germany, USA), and frozen at $-20^{\circ} \mathrm{C}$ until processing.

\section{HPV DNA extraction}

For DNA extraction, we used QIAamp DNA Mini and Blood Mini kits (Qiagen) according to manufacturer instructions. A sample was homogenized in a 2-mL microtube with $400 \mu \mathrm{L}$ buffer $\mathrm{AL}$ containing proteinase $\mathrm{K}$ and incubated at $56^{\circ} \mathrm{C}$ for $10 \mathrm{~min}$. Next, $400 \mu \mathrm{L}$ absolute ethanol was added to the sample, mixed, transferred to a spin column, and subjected to centrifugation at $5500 \mathrm{~g}$ for $1 \mathrm{~min}$. Subsequently, $500 \mu \mathrm{L}$ buffer AW1 was added to the column, which was centrifuged at $5500 \mathrm{~g}$ for $1 \mathrm{~min}$, and $500 \mu \mathrm{L}$ buffer AW2 was added and the sample was centrifuged at $15000 \mathrm{~g}$ for $3 \mathrm{~min}$. Finally, $200 \mu \mathrm{L}$ buffer AE was added, the column was centrifuged, and the collected sample was stored at $-20^{\circ} \mathrm{C}$.

Extracted DNA was quantified using a NanoVue unit (GE Healthcare Life Sciences, Little Chalfont, UK) and evaluated by amplification of the human $\beta$-globin gene.

\section{Detection of HPV}

HPV detection by PCR was carried out using a nested PCR approach with the primer pairs MY09/MY11 and GP5+/GP6+ (Invitrogen, Carlsbad, CA, USA) as described previously (Kleter et al., 1999).

The first round of amplification was carried out in a $25-\mu \mathrm{L}$ reaction volume by using 5 $\mu \mathrm{L}$ DNA, $8.7 \mu \mathrm{L}$ water, $2.5 \mu \mathrm{L}$ 10X PCR buffer (10 mM Tris-HCl, $\mathrm{pH} 8.5,50 \mathrm{mM} \mathrm{KCl}), 1.5 \mathrm{mM}$ $\mathrm{MgCl}_{2}, 10 \mathrm{mM}$ each dNTP, $30 \mu \mathrm{M}$ each primer (MY09 and MY11), and $0.5 \mu \mathrm{L}$ Platinum Taq DNA polymerase (Invitrogen). Amplification was performed according to the following protocol: 35 cycles at $94^{\circ} \mathrm{C}$ for $30 \mathrm{~s}, 51.5^{\circ} \mathrm{C}$ for $30 \mathrm{~s}, 72^{\circ} \mathrm{C}$ for $30 \mathrm{~s}$, followed by a final step at $72^{\circ} \mathrm{C}$ for $7 \mathrm{~min}$.

The second amplification was also carried out in a $25-\mu \mathrm{L}$ reaction volume by using $5 \mu \mathrm{L}$ amplified DNA, $9.7 \mu \mathrm{L}$ water, $2.5 \mu \mathrm{L} 10 \mathrm{X}$ PCR buffer, $1.5 \mathrm{mM} \mathrm{MgCl}_{2}, 10 \mathrm{mM}$ of each dNTP, 30 $\mu \mathrm{M}$ of each primer (GP5+ and GP6+), and $0.5 \mu \mathrm{L}$ Platinum Taq DNA polymerase. Amplification was performed as follows: $94^{\circ} \mathrm{C}$ for $5 \mathrm{~min}$, followed by 45 cycles at $94^{\circ} \mathrm{C}$ for $45 \mathrm{~s}, 40^{\circ} \mathrm{C}$ for 60 $\mathrm{s}$, and $72^{\circ} \mathrm{C}$ for $60 \mathrm{~s}$, and a final step at $72^{\circ} \mathrm{C}$ for $10 \mathrm{~min}$.

Amplification products were evaluated by electrophoresis on a 1.5\% agarose gel in $1 \mathrm{X}$ TBE buffer for $30 \mathrm{~min}$ at $5 \mathrm{~V} / \mathrm{cm}$ in a horizontal unit (Life Technologies, Carlsbad, CA, 
USA). Bands were stained with $0.1 \%$ Gel Red (Invitrogen) and visualized using an ultraviolet transilluminator (BioRad Laboratories, Hercules, CA, USA). Samples positive for HPV DNA were further subjected to sequence analysis.

Sequencing was performed at the Laboratory of Molecular Carcinogenesis, National Cancer Institute José Alencar Gomes da Silva (INCA), using the ET Dye Terminator Cycle Sequencing kit and automated sequencer MegaBACE 1000 (GE Healthcare) according to manufacturer instructions. Each reaction contained $2 \mu \mathrm{L}$ purified PCR product, 40 ng exonspecific oligonucleotides (sense or antisense), and $2 \mu \mathrm{L}$ kit reagent.

When an indeterminate result was obtained by sequencing, the sample DNA was subjected to allele-specific PCR for HPV 16. PCR amplification was carried out as described above using the primers E6-R 5'-ACCTCACGTCGCAGTAACGTTG-3' and E6-F 5'-GSGCGACCAGAAAGTTACCAG-3' (Rocha et al., 2012). The cycling protocol consisted of an initial denaturation step at $94^{\circ} \mathrm{C}$ for $5 \mathrm{~min}, 40$ cycles at $94^{\circ} \mathrm{C}$ for $1 \mathrm{~min}, 60^{\circ} \mathrm{C}$ for $1 \mathrm{~min}$, and $72^{\circ} \mathrm{C}$ for $1 \mathrm{~min}$, followed by a final extension at $72^{\circ} \mathrm{C}$ for $7 \mathrm{~min}$.

\section{Data analysis}

Data was analyzed using the Stata version 11 software for Windows. Data were initially subjected to descriptive analysis using the chi-square test. Multiple logistic regression was used to evaluate associations between HPV infection status and socio-demographic factors. The distribution of HPV genotypes in the study population is presented as frequencies and proportions. $\mathrm{P}<0.05$ was considered to be statistically significant.

\section{RESULTS}

The study included 97 women with cervical lesions; among them, 80 were diagnosed with low-grade lesions (82.4\%) and 17 with high-grade lesions $(17.6 \%)$, whereas 78 women were found to be positive for HPV DNA (80.4\%). Seventeen HPV types were identified in 63 women; HPV type was not determined for 15 patients (Table 1). The most prevalent viral types were HPV 16 (31.1\%), 18 (7.7\%), 58 (6.4\%), 6 (5.1\%), and 11 (5.1\%). High-risk viral types were detected in $69.2 \%$ of HPV-infected women (Table 1$)$.

Table 1. HPV type distribution in 78 samples from HPV-positive women in São Luís, Maranhão, Brazil (2013).

\begin{tabular}{lcrr}
\hline Risk HPV & HPV type & $\mathrm{N}$ & $\%$ \\
\hline High risk & 16 & 29 & 31.1 \\
& 18 & 6 & 7.7 \\
& 58 & 5 & 6.4 \\
& 35 & 2 & 2.6 \\
& 45 & 2 & 2.6 \\
& 33 & 1 & 1.3 \\
& 56 & 1 & 1.3 \\
Probable high-risk & 67 & 1 & 1.3 \\
& 68 & 1 & 1.3 \\
Low-risk & 69 & 1 & 1.3 \\
& 53 & 1 & 1.3 \\
& 66 & 4 & 5.1 \\
& 6 & 4 & 5.1 \\
& 11 & 1 & 2.6 \\
& 81 & 1 & 1.3 \\
& 44 & 15 & 1.3 \\
& 62 & 78 & 10.2 \\
\hline
\end{tabular}


Risk factors associated with cervical lesions were age and frequency of visits to the gynecologist (Tables 2 and 3).

Table 2. Multivariate analysis of social factors associated with cervical lesions in HPV-positive women from São Luís, Maranhão, Brazil (2013).

\begin{tabular}{|c|c|c|c|c|c|}
\hline & OR & $\mathrm{Z}$ & & & $P$ value \\
\hline Age (years) & 2.57 & 2.47 & 1.21 & 5.43 & 0.013 \\
\hline Literacy & 0.91 & -0.42 & 0.62 & 1.35 & 0.671 \\
\hline Marital status & 0.97 & -0.12 & 0.67 & 1.4 & 0.903 \\
\hline Ethnicity & 0.61 & -1.08 & 0.25 & 1.49 & 0.281 \\
\hline Visit to the gynecologist & 41.71 & 2.94 & 2.37 & 500.0 & 0.003 \\
\hline Age at menarche & 2.21 & 1.36 & 0.7 & 6.99 & 0.173 \\
\hline Age first intercourse & 1.16 & 0.22 & 0.29 & 4.58 & 0.825 \\
\hline Parity & 1.6 & 1.38 & 0.81 & 3.15 & 0.167 \\
\hline Lifetime number of sexual partners & 0.99 & -0.04 & 0.63 & 1.54 & 0.966 \\
\hline
\end{tabular}

$\mathrm{OR}=$ odds ratio $; 95 \% \mathrm{CI}=95 \%$ confidence interval.

Table 3. Analysis of risk factors associated with cervical lesions in HPV-positive women from São Luís, Maranhão, Brazil (2013).

\begin{tabular}{|c|c|c|c|c|c|}
\hline & \multicolumn{4}{|c|}{ Grade lesions } & \multirow[t]{3}{*}{$P$ value } \\
\hline & \multicolumn{2}{|c|}{ Low-grade } & \multicolumn{2}{|c|}{ High-grade } & \\
\hline & $\mathrm{N}$ & $\%$ & $\mathrm{~N}$ & $\%$ & \\
\hline Age (years) & & & & & 0.026 \\
\hline$<30$ & 44 & 55.0 & 4 & 23.5 & \\
\hline 30 to 49 & 29 & 35.0 & 7 & 47.1 & \\
\hline$>50$ & 8 & 10.0 & 5 & 29.4 & \\
\hline Literacy & & & & & 0.323 \\
\hline Illiterate & 4 & 5.0 & 2 & 11.8 & \\
\hline Elementary Education (complete) & 5 & 6.2 & 2 & 11.8 & \\
\hline Elementary Education (incomplete) & 16 & 20.0 & 2 & 11.8 & \\
\hline High school (complete) & 30 & 37.5 & 3 & 17.6 & \\
\hline High school (incomplete) & 16 & 20.0 & 7 & 41.1 & \\
\hline University (complete) & 7 & 8.8 & 1 & 5.9 & \\
\hline University (incomplete) & 2 & 2.5 & 0 & 0.0 & \\
\hline Marital status & & & & & 0.853 \\
\hline Single & 22 & 27.5 & 6 & 35.3 & \\
\hline Married & 38 & 47.5 & 7 & 41.2 & \\
\hline Consensual union & 18 & 22.5 & 3 & 23.5 & \\
\hline Method diagnosed CIN & & & & & $<0.001$ \\
\hline Pap smear & 66 & 82.6 & 0 & 0.0 & \\
\hline Directed biopsy (colposcopy) & 7 & 8.7 & 17 & 100.0 & \\
\hline Diagnostic conizations & 7 & 8.7 & 0 & 0.0 & \\
\hline Frequency of visit to the gynecologist before diagnosis of CIN & & & & & $<0.001$ \\
\hline Once every year & 20 & 25 & 1 & 5.9 & \\
\hline Once every 3 years & 0 & 0 & 6 & 35.3 & \\
\hline Never & 60 & 75 & 10 & 58.8 & \\
\hline Use of barrier method & & & & & 0.90 \\
\hline No & 58 & 72.5 & 5 & 82.4 & \\
\hline Yes (Condom) & 22 & 27.5 & 12 & 17.6 & \\
\hline
\end{tabular}

\section{DISCUSSION}

In our study, 78 (84.4\%) women with cervical lesions had HPV infection. This result is similar to the findings of Haghshenas et al. (2013) who examined 98 cervical samples and showed that $78(79.59 \%)$ were positive for HPV DNA. 
Among the 78 HPV-positive women identified in our study, 51(65.4\%) were infected with high-risk HPV types. This frequency was similar to that reported by Brismar-Wendel et al. (2009) who conducted population-based screening and found high-risk HPV serotypes in $71 \%$ of low-grade intraepithelial lesions.

The most prevalent high-risk HPV types were HPV 16 and 18, confirming the previously reported type-specific HPV distribution in 432 patients with invasive cervical carcinoma (Kasamatsu et al., 2012). The study also showed that $73.1 \%$ of HPV-positive cases were HPV 16 and 18; other common types included HPV 45, 33, 31, 52, 35, and 39. Seroprevalence of these HPV phenotypes was increased in HIV-positive patients or in those receiving immunosuppressive therapy, which is known to increase the risk of co-infections and viral persistence (Naucler et al., 2011; Nicol et al., 2013). In addition to HPV types 16 and 18, serotypes 31, 33, $35,39,45,51,52,56,58,59,68,73$, and 82 should be considered high-risk, and HPV 26, 53, and 66 can be classified as probable high-risk types (Muñoz et al., 2003).

The low-risk HPV types 6 and 11 are responsible for approximately $90 \%$ of genital wart (condylomata acuminata) cases, although the identification requires analysis of the innermost wart region because the surface area can contain multiple HPV types that are not necessarily involved in lesion pathogenesis (Hawkins et al., 2013). HPV 16 and 11 are sometimes observed in high-grade lesions and in anal cancer (Cornall et al., 2013). However, there are other types of low-risk HPV with a lower frequency, such as HPV 44, which were identified in our study in one patient. HPV 6 and 11 are also more prevalent in pregnant than in nonpregnant women, which is important for understanding the epidemiology of these HPV types in relation to the vertical transmission of HPV infection (Rombaldi et al., 2009; Naucler et al., 2011).

After HPV 16 and 18, HPV 45 is the 3rd most frequently detected serotype in cancer biopsies, and HPV 31 is most frequently detected together with HPV 16 in co-infections, regardless of the region of the female reproductive system (Baldez da Silva et al., 2012; Muñoz et al., 2003).

While high-grade HPV 58, 35, and 33 are the 6th, 7th, and 8th most common types, respectively, in invasive cervical cancer patients, other genotypes can also be classified as carcinogenic, such as HPV types 53 and 66, which are found in high-grade intraepithelial lesions (Meyer et al., 1998). Additionally, HPV 44 and 81 are regarded as low-grade serotypes because of their low frequency in patients with cervical neoplasia or cancer (Muñoz et al., 2003).

HPV 62 is considered to be a rare, highly divergent HPV type prone to mutagenesis. HPV 62 infection was detected in intraepithelial lesions similar to those produced by highly oncogenic HPV subtypes. This HPV serotype is relevant not only for women but also for their male sexual partners, as indicated by a case of penile cancer in a 23 -year-old man associated with HPV 62 infection. Such cases are primarily detected in younger populations; however, additional studies are needed to confirm this association (Meyer et al., 1998).

The unusual HPV serotype 69, which was previously associated with low-grade lesions, was found in a clinically aggressive plantar wart in a human immunodeficiency viruspositive patient. Thus, rare serotypes such as HPV 69 can also cause extremely cancerous dysplastic lesions that require immediate treatment and histopathological analysis if necessary (Whitaker et al., 2009).

Multiple infections were verified in 19.2\% of HPV-infected women (undetermined HPV). This finding was similar to the previously reported frequencies of $17.9 \%$ (Goldman et al., 2013) and 20.4\% (Carozzi et al., 2012). Women infected with multiple HPV serotypes are more prone to persistent infections with high viral loads and are therefore considered to be 
at high-risk for developing cervical cancer (Xi et al., 2009). More than half of HPV-positive men are infected with multiple types of HPV, which can be transmitted to their female partners (Rositch et al., 2012).

Patients with high-grade cervical lesions have tested positive for HPV DNA in 64 to $83 \%$ of cases (Corrêa et al., 2012). HPV genotyping has important applications in the screening, evaluation, and monitoring of low-grade cervical intraepithelial neoplasia (Peralta-Zaragoza et al., 2013).

Risk factors associated with cervical lesions in this study included the patient's age and frequency of visits to the gynecologist. Cervical lesions were more frequently observed in patients younger than 30 years, thus confirming the results obtained in other studies (BrismarWendel et al., 2009; Demers et al., 2012; Wiley et al., 2012). However, older subjects showed an increased prevalence of high-grade lesions compared to younger subjects who primarily had low-grade lesions $(\mathrm{P}<0.026)$.

The results also show that the Pap test was the most common diagnostic tool for lowgrade lesions $(\mathrm{P}<0.001)$. Cities that have implemented preventive screening showed a reduction in the incidence of cervical cancer (Bleggi et al., 2003).

A retrospective study based on cytopathological results revealed a high frequency of cases referred for colposcopy and histology (Albuquerque et al., 2012). An inevitable consequence of following this course carries the burden of secondary services and increased frequency of dispensable procedures (de Andrade, 2012). Such wasting of public resources may explain the low frequency of Pap screening in Latin America, which is approximately 50\% (Soneji and Fukui, 2013). Additionally, there may be a lack of knowledge regarding the importance of preventive HPV screening in the fight against cervical cancer, particularly among younger people with lower income and educational levels (de Lima et al., 2012).

However, it is necessary to increase the range of preventive screening in the general population, particularly among women who have never undergone this examination and are therefore more likely to develop cervical cancer (Nascimento et al., 2012). The most important constraint is the low coverage by Pap screening. Although the number of women tested has increased, the testing frequency remains insufficient to result in an impact because of major regional economic and social inequalities (de Andrade, 2012).

Educational measures have been shown to reduce the number of cervical cancer cases, as adequate information can induce changes in sexual behavior and/or attitudes to health care. This information can be provided by any health professional, and it has been observed that doctor visits are often followed by preventive examination (Sogukpinar et al., 2013). In this study, we found that women who had never visited the gynecologist have a greater risk of developing both low- and high-grade cervical lesions. Medical consultation ensures not only the monitoring and prevention of the onset and progression of neoplastic cervical lesions but also the use of preventive measures such as condom use and behavioral changes (Soneji and Fukui, 2013). This is important because women who engage in risky behavior have a greater chance of developing cervical lesions as HPV is primarily sexually transmitted. One study found that condom usage not only reduced the risk of acquiring HPV but also resulted in HPV clearance by $30 \%$ (Pierce Campbell et al., 2013).

Therefore, to prevent the spread of HPV infections, it is essential to use condoms during sexual intercourse, even with only 1 sexual partner, as well as to implement other preventive measures. These measures are particularly important for women who have never undergone testing for cervical lesions. 


\section{ACKNOWLEDGMENTS}

Research supported by FAPEMA. We would also like to acknowledge all of the study participants. We also thank INCA for sequencing services.

\section{REFERENCES}

Albuquerque ZB, Manrique EJ, Tavares SB, Silva e Souza AC, et al. (2012). Women with atypical, precursor lesions and invasive cervical cancer: behaviors according to the recommendations of the Ministry of Health. Rev. Bras. Ginecol. Obstet. 34: 248-253.

Andall-Brereton GM, Hosein F, Salas RA, Mohammed W, et al. (2011). Human papillomavirus genotypes and their prevalence in a cohort of women in Trinidad. Rev. Panam. Salud Publica 29: 220-226.

Ayres AR and Silva GA (2010). Cervical HPV infection in Brazil: systematic review. Rev. Saude Publica 44: 963-974.

Baldez da Silva MF, Guimaraes V, Silva MA, Medeiros do Amaral CM, et al. (2012). Frequency of human papillomavirus types 16, 18, 31, and 33 and sites of cervical lesions in gynecological patients from Recife, Brazil. Genet. Mol. Res. 11: 462-466.

Bleggi Torres LF, Werner B, Totsugui J, Collaco LM, et al. (2003). Cervical cancer screening program of Parana: costeffective model in a developing country. Diagn. Cytopathol. 29: 49-54.

Brismar-Wendel S, Froberg M, Hjerpe A, Andersson S, et al. (2009). Age-specific prevalence of HPV genotypes in cervical cytology samples with equivocal or low-grade lesions. Br. J. Cancer 101: 511-517.

Bruni L, Diaz M, Castellsague X, Ferrer E, et al. (2010). Cervical human papillomavirus prevalence in 5 continents: metaanalysis of 1 million women with normal cytological findings. J. Infect. Dis. 202: 1789-1799.

Carozzi F, Ronco G, Gillio-Tos A, De Marco L, et al. (2012). Concurrent infections with multiple human papillomavirus (HPV) types in the New Technologies for Cervical Cancer (NTCC) screening study. Eur. J. Cancer 48: 1633-1637.

Cornall AM, Roberts JM, Garland SM, Hillman RJ, et al. (2013). Anal and perianal squamous carcinomas and high-grade intraepithelial lesions exclusively associated with "low-risk" HPV genotypes 6 and 11. Int. J. Cancer 133: 2253-2258.

Correa FM, Russomano FB and Oliveira CA (2012). Colposcopic triage methods for detecting cervical intraepithelial neoplasia grade 3 after cytopathological diagnosis of low-grade squamous intraepithelial lesion: a systematic review on diagnostic tests. Sao Paulo Med. J. 130: 44-52.

de Andrade JM (2012). Limitations of the success of screening for cervical cancer in Brazil. Rev. Bras. Ginecol. Obstet. 34: 245-247.

de Freitas AC, Gurgel AP, Chagas BS, Coimbra EC, et al. (2012). Susceptibility to cervical cancer: an overview. Gynecol. Oncol. 126: 304-311.

de Lima Rocha MG, Faria FL, Gonçalves L, Souza Mdo C, et al. (2012). Prevalence of DNA-HPV in male sexual partners of HPV-infected women and concordance of viral types in infected couples. PLoS One 7: e40988.

Demers AA, Shearer B, Severini A, Lotocki R, et al. (2012). Distribution of human papillomavirus types, cervical cancer screening history, and risk factors for infection in Manitoba. Chronic Dis. Inj. Can. 32: 177-185.

Fernandes JV, Meissner Rde V, de Carvalho MG, Fernandes TA, et al. (2009). Prevalence of HPV infection by cervical cytologic status in Brazil. Int. J. Gynaecol. Obstet. 105: 21-24.

Goldman B, Rebolj M, Rygaard C, Preisler S, et al. (2013). Patterns of cervical coinfection with multiple human papilloma virus types in a screening population in Denmark. Vaccine 31: 1604-1609.

Haghshenas M, Golini-Moghaddam T, Rafiei A, Emadeian O, et al. (2013). Prevalence and type distribution of high-risk human papillomavirus in patients with cervical cancer: a population-based study. Infect. Agent. Cancer 8: 20.

Hawkins MG, Winder DM, Ball SL, Vaughan K, et al. (2013). Detection of specific HPV subtypes responsible for the pathogenesis of condylomata acuminata. Virol. J. 10: 137.

Jemal A, Bray F, Center MM, Ferlay J, et al. (2011). Global cancer statistics. CA Cancer J. Clin. 61: 69-90.

Kasamatsu E, Cubilla AL, Alemany L, Chaux A, et al. (2012). Type-specific human papillomavirus distribution in invasive cervical carcinomas in Paraguay. A study of 432 cases. J. Med. Virol. 84: 1628-1635.

Katki HA, Schiffman M, Castle PE, Fetterman B, et al. (2013). Five-year risks of CIN 3+ and cervical cancer among women who test Pap-negative but are HPV-positive. J. Low. Genit. Tract. Dis. 17: S56-S63.

Kleter B, van Doorn LJ, Schrauwen L, Molijn A, et al. (1999). Development and clinical evaluation of a highly sensitive PCR-reverse hybridization line probe assay for detection and identification of anogenital human papillomavirus. $J$. Clin. Microbiol. 37: 2508-2517.

Li N, Franceschi S, Howell-Jones R, Snijders PJ, et al. (2011). Human papillomavirus type distribution in 30,848 invasive 
cervical cancers worldwide: Variation by geographical region, histological type and year of publication. Int. J. Cancer 128: 927-935.

Meyer T, Arndt R, Christophers E, Beckmann ER, et al. (1998). Association of rare human papillomavirus types with genital premalignant and malignant lesions. J. Infect. Dis. 178: 252-255.

Muñoz N, Bosch FX, de Sanjosé S, Herrero R, et al. (2003). Epidemiologic classification of human papillomavirus types associated with cervical cancer. N. Engl. J. Med. 348: 518-527.

Nascimento MI, Silva GA and Monteiro GT (2012). Previous history of Pap smears and cervical cancer: a case-control study in the Baixada Fluminense, Rio de Janeiro State, Brazil. Cad. Saude Publica 28: 1841-1853.

Naucler P, Mabota da CF, da Costa JL, Ljungberg O, et al. (2011). Human papillomavirus type-specific risk of cervical cancer in a population with high human immunodeficiency virus prevalence: case-control study. J. Gen. Virol. 92: 2784-2791.

Nicol AF, Grinsztejn B, Friedman RK, Veloso VG, et al. (2013). Seroprevalence of HPV vaccine types 6, 11, 16 and 18 in HIV-infected and uninfected women from Brazil. J. Clin. Virol. 57: 147-151.

Peralta-Zaragoza O, Deas J, Gómez-Cerón C, García-Suastegui WA, et al. (2013). HPV-based screening, triage, treatment, and followup strategies in the management of cervical intraepithelial neoplasia. Obstet. Gynecol. Int. 2013: 912780.

Pierce Campbell CM, Lin HY, Fulp W, Papenfuss MR, et al. (2013). Consistent condom use reduces the genital human papillomavirus burden among high-risk men: the HPV infection in men study. J. Infect. Dis. 208: 373-384.

Rombaldi RL, Serafini EP, Mandelli J, Zimmermann E, et al. (2009). Perinatal transmission of human papilomavirus DNA. Virol. J. 6: 83.

Rositch AF, Poole C, Hudgens MG, Agot K, et al. (2012). Multiple human papillomavirus infections and type competition in men. J. Infect. Dis. 205: 72-81.

Sogukpinar N, Saydam BK, Can HO, Hadimli A, et al. (2013). Assessment of cervical cancer risk in women between 15 and 49 years of age: case of Izmir. Asian Pac. J. Cancer Prev. 14: 2119-2125.

Soneji S and Fukui N (2013). Socioeconomic determinants of cervical cancer screening in Latin America. Rev. Panam. Salud Publica 33: 174-182.

Whitaker JM, Palefsky JM, Da Costa M, King CM, et al. (2009). Human papilloma virus type 69 identified in a clinically aggressive plantar verruca from an HIV-positive patient. J. Am. Podiatr. Med. Assoc. 99: 8-12.

Wiley DJ, Masongsong EV, Lu S, Heather LS, et al. (2012). Behavioral and sociodemographic risk factors for serological and DNA evidence of HPV6, 11, 16, 18 infections. Cancer Epidemiol. 36: e183-e189.

Xi LF, Hughes JP, Edelstein ZR, Kiviat NB, et al. (2009). Human Papillomavirus (HPV) type 16 and type 18 DNA Loads at Baseline and Persistence of Type-Specific Infection during a 2-year follow-up. J. Infect. Dis. 200: 1789-1797.

Zandberg DP, Bhargava R, Badin S and Cullen KJ (2013). The role of human papillomavirus in nongenital cancers. $C A$ Cancer J. Clin. 63: 57-81. 